\title{
Proceso de declive del buglere ${ }^{1}$
}

\section{(The Decline of Buglere)}

Isabel Cristina Bolaños Villalobos ${ }^{2}$

Universidad Nacional, Costa Rica

\begin{abstract}
RESUMEN
Se describe el acelerado proceso del declive en el que se halla el buglere costarricense, a partir de varias tipologías utilizadas para el estudio de lenguas en riesgo de extinción. Teniendo como punto de referencia estudios previos, se comentan factores concurrentes que se han dado entre la comunidad hablante de esa lengua (socioculturales, principalmente), que han conducido al paso de un estado obsolescente al de indiferencia y de su próxima extinción.
\end{abstract}

\begin{abstract}
A description is provided of the rapid decline of Costa Rican Buglere, based on several typologies used to study languages in danger of extinction. Using previous studies as reference points, attention is given to concurrent factors, most of which are sociocultural, occurring between the speakers of that language, which have led it from the state of obsolescence to that of indifference, and extinction in the near future.
\end{abstract}

Palabras clave: obsolescencia, muerte de lenguas, actitudes lingüísticas, vitalidad lingüística, documentación.

Key words: obsolescence, languages extinction, linguistic attitudes, linguistic vitality, documentation.

1 Recibido: 11 de abril de 2019; aceptado: 27 de agosto de 2019. En este artículo se desarrollan en detalle algunos conceptos presentados en el IV Congreso Internacional de la Asociación Centroamericana de Lingüística (ACALING), Universidad Don Bosco San Salvador, El Salvador. 28, 29, 30 de agosto de 2017. Se puede consultar también: https://prezi.com/vwkvt_msrhbr/ declive-del-buglere/.

2 Escuela de Literatura y Ciencias del Lenguaje. Correo electrónico: isabel.bolanos.villalobos@una.ac.cr

LETRAS 67 (2020), ISSN 1409-424X; EISSN 2215-4094

Doi: http://dx.doi.org/10.15359/rl.1-67.5

www.revistas.una.ac.cr/index.php/letras 


\section{Introducción}

La población indígena buglé costarricense se encuentra en el sur del país, en el Territorio Indígena Guaymí, de San Vito de Coto Brus. Los hablantes del buglere emigraron hacia Costa Rica desde Panamá en la década de 1950, siguiendo el grupo étnico guaymí, con el que conviven "compartiendo la misma cultura», pero lenguas distintas, tal y como la misma población buglé lo indica. Sin embargo, esta coexistencia ha ido en detrimento de su lengua y de su cultura, debido a la «superioridad cultural» de los guaymíes, más numerosos y que presentan una formación social mucho más fuerte. Los guaymíes han ido poco a poco absorbiendo a los buglés al punto de que en censo nacional de 2011 la población buglé no fue contabilizada como grupo étnico costarricense, sino como de origen guaymí. Por esto, no existen datos de la cantidad exacta de pobladores buglés, en Costa Rica, pero se considera que hay alrededor de doscientas personas que habitan ese territorio.

La estrecha relación vertical de los guaymíes con los buglés es evidente en situaciones sociales. Los buglés, quienes a su llegada a Costa Rica fueron equívocamente identificados como «guaymíes sabaneros» por considerarlos hablantes de un dialecto guaymí, eliminaron la denominación guaymí y mantuvieron la de sabaneros, la cual utilizan actualmente para autodenominarse ${ }^{3}$. En cuanto a la superioridad social ejercida sobre la población buglé, no hay estudios antropológicos que indiquen su razón; pero según Francisco Rodríguez, informante mayor de la comunidad, las mujeres buglés preferían a los hombres guaymíes por ser estos más fuertes y altos; consideraban que eran mejor para la cacería y la pesca. Con base en esto apareció tal superioridad social y cultural, que probablemente haya sido la causa de un bilingüismo unidireccional en los matrimonios entre guaymíes

3 J. Diego Quesada, Gramática del buglere (Quito: Abya Yala, 2012): 17-23 (17). 
y buglés. Esto significa que en una familia entre un buglé y un guaymí, sin importar cuál de los dos esposos sea de cuál etnia, se hablará mayoritariamente el guaymí. Los hijos de esa familia serán guaymíes, a pesar de que su madre o padre sean buglés.

En el Territorio Indígena Guaymí funciona un colegio público y varias escuelas de primaria distribuidas por los diferentes caseríos. Para lo que concierne a este trabajo se han considerado las poblaciones de La Casona, Kiabto y Betania. En la cabecera del territorio, el caserío La Casona, existe una escuela de primaria, un colegio de secundaria, un centro de atención de salud (EBAIS), un Centro de Educación y Nutrición y Centro Infantil de Atención Integral CENCINAI, dos pequeñas tiendas de comestibles e iglesias de distintas denominaciones religiosas. La Casona se encuentra a 16 kilómetros del centro de San Vito, con un camino lastrado de cinco kilómetros desde la carretera principal.

Las poblaciones de Betania y Kiabto están más lejanas que La Casona y su acceso es mucho más complicado según las condiciones del camino y el clima. La escuela primaria y el colegio secundario son instituciones de educación que trabajan bajo la nominación de colegio o escuela indígena, también existente en el sistema de educación pública del país. Por ello, a los estudiantes se les imparte tan solo tres clases de lengua materna y dos de cultura, únicamente en la escuela. En secundaria reciben clases de español, inglés o francés, pero no de sus lenguas maternas. No fue sino hasta 2016 cuando el Ministerio de Educación Pública encargó a una maestra para enseñar la lengua buglere en las escuelas primaras de La Casona, Kiabto y Betania; anteriormente a los niños buglés se les impartían clases de guaymí. Además, pese a que el buglere es la lengua materna de la maestra, no es una docente titulada. Con respecto a las clases de cultura, sólo se imparten de cultura guaymí ya que como se indicó, hasta los mismos maestros consideran que es «la misma cultura». Esto es una muestra 
de la superioridad guaymí ya que al ser lenguas distintas las culturas como productos de la lengua debieron de haber sido distintas antes de la asimilación de la población actual buglé de la cultura guaymí. El detrimento de su cultura y lengua es tan palpable que sus propios pobladores desconocen los rasgos culturales particulares de su cultura ante la guaymí.

La población buglé que asiste a la escuela, según datos proporcionados por el director y la maestra de lengua buglere de la escuela de La Casona, San Vito, correspondía en 2016 a treinta niños buglés en la escuela de La Casona, siete en Kiabto, y cuatro en Betania, para un total de cuarenta y un niños buglés en el sistema de educación. Sus edades oscilan entre siete y trece años, y se considera que quizá la mitad entienden su lengua, y solo la cuarta parte son capaces de hablarla.

Todos los grupos minoritarios del país, incluidos los indígenas buglés, no han recibido apoyo oficial para fortalecer y revitalizar sus lenguas y culturas. El mismo sistema de educación pública prioriza enseñarles a los niños del territorio indígena — declarado patrimonio cultural - inglés u otra lengua extranjera antes que su lengua materna. La enseñanza prioritaria es en español. Es manifiesta la carencia de políticas claras y eficaces en pro del patrimonio cultura indígena costarricense.

\section{Tipología del estado de lenguas y caracterización del buglere}

Según la UNESCO${ }^{4}$, una lengua se encuentra en peligro de extinción cuando cada vez menos pobladores la utilizan como medio de comunicación en ámbitos de educación, comunicación familiar, comercio y actividades religiosas culturales. Esto implica a una disminución significativa en el número de hablantes, con cada vez

4 UNESCO, «Vitalidad y peligro de desaparición de las lenguas», Grupo especial de expertos sobre las lenguas en peligro convocado por la UNESCO, Reunión Internacional de Expertos sobre el programa de la UNESCO «Salvaguardia de las Lenguas en Peligro», París, 10-12 de marzo de 2003, <http://www.unesco.org/new/fileadmin/MULTIMEDIA/HQ/CLT/ pdf/LVE_Spanish_EDITED\%20FOR\%20PUBLICATION.pdf>. 
menos hablantes adultos y una merma de niños. Existen varias categorizaciones para determinar el grado de declive de las lenguas en peligro de extinción. El propósito, aquí, es mostrar, mediante el uso de diversas escalas, cómo en el transcurso de menos de diez años, la lengua buglere ha sufrido un acelerado declive.

\section{Estados de salud de una lengua}

La clasificación muy conocida de lenguas en declive, establecida por Bauman ${ }^{5}$, identifica cinco niveles de estado de las lenguas indígenas en comparación con el inglés de Estados Unidos. El factor primordial que determina el estado de salud de una lengua es la población hablante, principalmente la población infantil hablante. Brevemente se describen las categorías:

Florecientes: son las lenguas que cuentan con hablantes monolingües de todas las edades, lo que conlleva un crecimiento en la población hablante. Se utilizan para todas las situaciones sociales y la lengua se adapta a la cultura cambiante de la población.

Duraderas: al igual que las lenguas en la categoría anterior, una lengua duradera cuenta con una alta valoración por parte de la comunidad. Sin embargo, una lengua duradera ha cedido territorio a la dominante, lo que provoca situaciones sociales que sólo se realicen en la lengua dominante. Aun así, la lengua como ente vivo sigue adaptándose a la cultura de la comunidad.

Declinantes: la población hablante de una lengua declinante es para entonces una población de mayor edad; no hay tantos jóvenes que la hablan con fluidez. A pesar de que la población puede continuar creciendo, el sector hablante disminuye al ser en su mayoría analfabetos en la lengua. En el aspecto cultural, una lengua declinante ha cedido espacio para que la lengua dominante se utilice en situaciones que anteriormente solo se daban en la lengua declinante.

5 James Bauman, A Guide to Issues in Indian Language Retention (Washington: Center for Applied Linguistics, 1980) 5-20036 (5). 
Obsolescentes: los hablantes de esta categoría de lengua son solo adultos, y estos no la enseñan a los niños, por lo cual el número de hablantes decrece rápidamente. Para este nivel toda la población es bilingüe y utiliza la lengua dominante preferiblemente en todas las situaciones. La lengua materna que permanece ya no es flexible, ni se adapta al cambio cultural.

Extintas: este nivel de declive se refiere a aquellas lenguas que no tienen hablantes nativos vivos. Estas lenguas se conocen y estudian gracias a los documentos escritos o grabaciones existentes, pero al no haber hablantes vivos no hay lengua viva.

Quesada ${ }^{6}$ aplicó esa clasificación al buglere y concluye que «el buglere se encuentra entre declinante y obsolescente». Con base en el análisis realizado en ese momento a la población buglé, consideraba positivo $(+)$ el factor correspondiente a la cantidad de hablantes y su grado de bilingüismo, pero en fase media $( \pm)$ la proporción de hablantes con respecto al total de población. Los factores de fluidez de los hablantes jóvenes, la preferencia por la lengua materna y la capacidad de adaptación de la lengua a la cultura hablante se catalogaron como negativos (-). Quesada indica como posible causa del estado de la lengua buglere la asimilación cultural a la cultura guaymí, la «obligación» no explícita de las leyes gubernamentales costarricenses (que no valoran la diversidad étnica y cultural), y la baja autoestima cultural que se ha desarrollado entre los bugles por la mezcla de las dos anteriores, sumado a la lejanía de la población buglé residente en Panamá.

\section{Tipos de lenguas y sus hablantes de Quesada}

Quesada ${ }^{7}$ introduce el concepto de fase crítica para al momento crucial en que «se decide si la lengua se va a proteger o si se va a descuidar para que se extinga». La sobrevivencia de la lengua está

6 J. Diego Quesada, «El buglere: lengua obsolescente», Letras 43 (2008a): 39-50 (43). Esta tipología contempla las siguientes categorías: 1. resistentes, 2 . vegetantes, 3. obsolescentes, 4 . indiferentes.

7 J. Diego Quesada, «Las lenguas chibchas y sus hablantes: resistencia, obsolescencia e indiferencia», Antonio Palmisano, ed., Identità delle Comunità Indigene del Centro America, Messico e Caraibi: aspetti culturali e antropologici (Roma: IILA, 2008b) 4-12 (4). 
muy relacionada con el papel que la población hablante considera que desempeña en la cohesión y preservación de la cultura y su propia sobrevivencia como grupo étnico. La actitud de la población hacia su lengua y su valoración son claves para la revitalización. De no contarse con estos factores, a la lengua no se le ha destinado más camino que su extinción. Quesada propone una nueva tipología para caracterizar las lenguas en fase crítica. A continuación, se detallan los cuatro niveles y actitudes de hablantes que las determinan:

Resistentes: «son lenguas cuyos hablantes poseen una consciencia y un orgullo profundo de sus lenguas, las cultivan, las enseñan a las nuevas generaciones, y utilizan la lengua como verdadero símbolo de identidad $»^{8}$. Muchos de este tipo de hablantes se aíslan del contacto con la cultura foránea como medida de preservación de su lengua y su cultura, con lo que refuerzan su lengua como símbolo de identidad.

Vegetantes: las lenguas ubicadas en esta condición son las que han sobrevivido más por fuerza del destino que por una decisión consciente de sus hablantes. Su preservación se debe al aislamiento geográfico y cultural de su población. Al acercarse esta más a los centros de población que están en contacto con otras leguas se manifiesta más su debilidad y descuido. Entre más aislamiento mayor la preservación de la lengua.

Obsolescentes: en el tercer nivel de la fase crítica de una lengua, «la transmisión generacional se ve interrumpida total o parcialmente por factores como la migración, la poca población, [y/o] la integración a la cultura criolla»?.

Indiferentes: se refiere a aquellas lenguas «cuyos hablantes no muestran interés en preservar su lengua, e incluso muestran cierta vergüenza lingüística» $\rangle^{10}$. La población manifiesta su desinterés por mantener la lengua. Cualquier uso social, religioso, o cultural que ésta haya tenido, ya no es útil.

8 Quesada (2008b), 12.

9 Quesada (2008b), 12.

10 Quesada (2008b), 12. 
En esta tipología, Quesada utiliza la lengua buglere como ejemplo en la caracterización de las lenguas obsolescentes. Considera que debido a la migración guaymí, a la interacción con las culturas indígena dominante - guaymí-y a la cultura criolla mestiza nacional, las nuevas generaciones cada vez hablan menos la lengua. Había más presencia de la lengua buglere en ambientes íntimos familiares. Quesada considera que «el abandono de la lengua no se puede achacar —al menos directamente - al español. Es muy probable que esa asimilación a la cultura guaymí sea un mecanismo de sobrevivencia étnica; es decir, que los buglés sientan que solo pueden sobrevivir como indígenas "bajo el ala" de un grupo por ellos percibido como fuerte» ${ }^{11}$.

\section{Factores para evaluar la vitalidad de una lengua de la UNESCO}

La UNESCO ${ }^{12}$ instituye que «la diversidad lingüística es esencial en el patrimonio de la humanidad. Cada lengua encarna la sabiduría cultural única de un pueblo. Por consiguiente, la pérdida de cualquier lengua es una pérdida para toda la humanidad». En la 31. ${ }^{a}$ reunión de la Conferencia General de la UNESCO, de octubre de 2001, se adopta la «Declaración Universal sobre la Diversidad Cultural», que reconoce el papel fundamental de la diversidad lingüística y se recomienda tomar medidas para «sostener la diversidad lingüística de la humanidad y apoyar la expresión, la creación y la difusión del mayor número posible de lenguas» ${ }^{13}$. Para ello se formulan nueve factores para evaluar la vitalidad de la lengua y su estado de peligro, calibrar las actitudes hacia ella y evaluar la urgencia del trabajo de documentación. A su vez, cada factor se subdivide en cinco grados de estado. En el resto de esta subsección se aplican esos factores al buglere según nuestra experiencia de campo. El análisis de los factores no se presenta en orden numérico sino de importancia o presencia de pruebas en la población en estudio.

11 J. Diego Quesada, J. «¿Indiferencia ante la indiferencia?», Ponencia presentada ante la XX Feria Internacional del Libro de Antropología en México, Museo de Antropología (2008c): 9.

12 UNESCO, 1.

13 UNESCO, 3. 
Factor 1: Transmisión intergeneracional de la lengua. «El factor más utilizado para evaluar la vitalidad de una lengua es el de si se transmite o no de una generación a la siguiente», sostiene Fish$\operatorname{man}^{14}$. Aquí la UNESCO establece una escala de cinco grados de esta transmisión (ver cuadro 1).

Cuadro 1. Factor 1: Transmisión intergeneracional de la lengua

\begin{tabular}{|l|c|l|}
\hline Grado de vitalidad & Grado & Población de hablantes \\
\hline no corre peligro & 5 & $\begin{array}{l}\text { La lengua es utilizada por todos los grupos de } \\
\text { edad, incluidos los niños. }\end{array}$ \\
\hline vulnerable & 4 & $\begin{array}{l}\text { La lengua es utilizada por algunos niños en } \\
\text { todos los ámbitos, y por todos los niños en } \\
\text { ámbitos restringidos. }\end{array}$ \\
\hline claramente en peligro & 3 & $\begin{array}{l}\text { La lengua es utilizada sobre todo por la } \\
\text { generación parental para arriba. }\end{array}$ \\
\hline seriamente en peligro & 2 & $\begin{array}{l}\text { La lengua es utilizada sobre todo por la } \\
\text { generación de los abuelos para arriba. }\end{array}$ \\
\hline en situación crítica & 1 & $\begin{array}{l}\text { La lengua es utilizada por muy pocos } \\
\text { hablantes, fundamentalmente de la generación } \\
\text { de los bisabuelos. }\end{array}$ \\
\hline extinta & 0 & Ya no quedan hablantes. \\
\hline
\end{tabular}

Fuente: UNESCO, 7.

Factor 2: Número absoluto de hablantes. En la comunidad buglé costarricense, los niños no aprenden en su hogar la lengua como materna. Algunos padres les hablan a los hijos en su lengua materna, pero por lo general los niños no contestan en ella. Aquí hay una clara diferencia entre los niños mayores y los menores. Los primeros hablan, lo segundos muy poco. Algunos niños indican que sus padres «los llaman en buglere» o les dan instrucciones en la lengua; sin embargo, ellos no tienen la competencia para responder. Más allá de instrucciones diarias o expresiones lingüísticas fijas, la lengua casi no se utiliza en el hogar en conversaciones espontáneas. A partir de ello, se concluye que la lengua está en un grado 3, claramente en peligro.

14 UNESCO, 6. 
Factores 2: Número absoluto de hablantes; y 3: Proporción de hablantes en el conjunto de la población. Pese a que no se puede establecer el número absoluto de hablantes necesarios para que una lengua continúe con vida, la UNESCO afirma que «una comunidad de hablantes pequeña está siempre en peligro. Una población pequeña es mucho más vulnerable que una grande a ser diezmada (debido a enfermedad, guerra o desastre natural, por ejemplo)» ${ }^{15}$.

La población buglé en Costa Rica está invisibilizada ${ }^{16}$. Tomando los datos del censo nacional, Constenla dice: «En la actualidad, las lenguas indígenas territoriales de Costa Rica son cuatro: bribri, cabécar, guaimí y guatuso». La cantidad de hablantes buglere es tan pequeña que en el censo de 2000 no aparece como una población minoritaria del país. Es probable que sus miembros fueron contados dentro de la población guaymí por compartir el territorio y por haber sido los buglés asimilados culturalmente. La versión electrónica del Summer Institute of Linguistics tampoco lo incluye en lo referente a las lenguas de Costa Rica, aunque sí como lengua de Panamá, de la que señala «Speakers of Sabanero are few and integrated among the Guaymí ${ }^{17}$. Quesada ${ }^{18}$ considera que apenas un $50 \%$ de esos 200 nativos buglés en Costa Rica habla con fluidez. ¿Qué ocurriría si viniera una catástrofe y murieran 100 buglés, el $50 \%$ de la población?

15 UNESCO, 7.

16 Adolfo Constela Umaña, «La diversidad lingüística de Costa Rica: las lenguas indígenas», Revista de Filología y Lingüistica 37 (2011): 93-106 (98).

17 Summer Institute of Linguistics (SIL), «Languages of the World: Languages of Costa Rica», Ethnologue, <www.sil.org>. Para Costa Rica, puede consultarse específicamente: https://www.ethnologue.com/13/countries/Cost.html; o para Panamá: https://www.ethnologue.com/13/countries/ Pana.html

18 Quesada (2012), 18. 
Cuadro 2. Factor 3: Proporción de hablantes en el conjunto de la población de referencia

\begin{tabular}{|l|c|l|}
\hline Grado de vitalidad & Grado & $\begin{array}{c}\text { Proporción de hablantes en el conjunto de } \\
\text { la población de referencia }\end{array}$ \\
\hline no corre peligro & 5 & Todos hablan la lengua. \\
\hline vulnerable & 4 & Casi todos hablan la lengua. \\
\hline claramente en peligro & 3 & La mayoría habla la lengua. \\
\hline seriamente en peligro & 2 & Una minoría habla la lengua. \\
\hline en situación crítica & 1 & Muy pocos hablan la lengua. \\
\hline extinta & 0 & Nadie habla la lengua. \\
\hline
\end{tabular}

Fuente: UNESCO, 8.

Esta situación hace pensar que el buglere está claramente en peligro de desaparecer. En cuanto a la proporción de hablantes en el conjunto de la población (ver cuadro 2), según cifras constatadas en el último año, de 41 niños buglés matriculados en la escuela menos de una cuarta parte lo hablan. Se puede decir entonces que el buglere se encuentra en grado 1: situación crítica, en que muy pocos lo hablan.

Factor 4: Cambios en los ámbitos de utilización de la lengua. En este factor se evalúa dónde, con quién y en qué asuntos se utiliza la lengua para su transmisión intergeneracional. El guaymí se utiliza en la escuela, en compras de comestibles y en la mayoría de las relaciones entre los pobladores mientras que el buglere se utiliza sólo en ámbitos cotidianos a lo interno del hogar. Los buglés no cuentan con una organización cultural y social activa; no hay actividades religiosas, administrativas y casi ni educativas que se dan en esta lengua. En el Festival Cultural Indígena (2017) del Liceo de La Casona, se efectuó una exposición de actividades culturas y religiosas del Territorio Indígena. En la mayoría de los casos se empleó el guaymí; la minoría el español. El buglere solo se mencionó como parte de cultura guaymí-buglere, pero el idioma no se utilizó. Todos estos factores indican que el buglere se usa en «ámbitos muy restringidos», como se puede ver en el cuadro 3. 
Cuadro 3. Factor 4: Cambios en el ámbito de utilización de la lengua

\begin{tabular}{|l|c|l|}
\hline Grado de vitalidad & Grado & \multicolumn{1}{|c|}{ Ámbitos y funciones } \\
\hline uso universal & 5 & $\begin{array}{l}\text { La lengua se utiliza en todos los ámbitos y } \\
\text { para todas las funciones. }\end{array}$ \\
\hline paridad plurilingüe & 4 & $\begin{array}{l}\text { Se pueden emplear dos o más lenguas en la } \\
\text { mayoría de los ámbitos sociales y para la } \\
\text { mayoría de las funciones. }\end{array}$ \\
\hline ámbitos decrecientes & 3 & $\begin{array}{l}\text { La lengua se utiliza en el ámbito doméstico } \\
\text { y para muchas funciones, pero la lengua } \\
\text { dominante empieza a penetrar incluso en el } \\
\text { ambiente familiar. }\end{array}$ \\
\hline $\begin{array}{l}\text { ámbitos limitados o } \\
\text { formales }\end{array}$ & 2 & $\begin{array}{l}\text { La lengua se utiliza en ámbitos sociales } \\
\text { limitados y para varias funciones. }\end{array}$ \\
\hline ámbitos muy limitados & 1 & $\begin{array}{l}\text { La lengua se utiliza sólo en un número muy } \\
\text { restringido de ámbitos y para muy pocas } \\
\text { funciones. }\end{array}$ \\
\hline extinta & 0 & $\begin{array}{l}\text { La lengua no se utiliza en ningún ámbito para } \\
\text { ninguna función. }\end{array}$ \\
\hline
\end{tabular}

Fuente: UNESCO, 9.

Factor 5: Referente a la respuesta a los nuevos ámbitos y medios de comunicación. Se encuentra en un grado inactivo (ver cuadro 4). El buglere costarricense no se utiliza en ningún nuevo ámbito. En 2016 empezó la enseñanza del buglere a los 41 niños matriculados en las escuelas; antes de eso los niños buglés asistían a clases de lengua y cultura guaymí, donde se les enseñaba implícitamente que la lengua para comunicarse en su comunidad era el guaymí. En los demás tipos del sistema de enseñanza, domina el español, que sobrepasa incluso al guaymí. Esto indica que el buglere costarricense está inactivo en el desarrollo diario de la población. 
Cuadro 4. Factor 5: Referente a la respuesta a los nuevos ámbitos y medios de comunicación

\begin{tabular}{|l|c|l|}
\hline Grado de vitalidad & Grado & $\begin{array}{l}\text { Nuevos ámbitos y medios aceptados por la } \\
\text { lengua en peligro }\end{array}$ \\
\hline dinámica & 5 & $\begin{array}{l}\text { La lengua se utiliza en todos los nuevos } \\
\text { ámbitos. }\end{array}$ \\
\hline robusta/activa & 4 & $\begin{array}{l}\text { La lengua se utiliza en la mayoría de los } \\
\text { nuevos ámbitos. }\end{array}$ \\
\hline pasiva & 3 & $\begin{array}{l}\text { La lengua se utiliza en muchos nuevos } \\
\text { ámbitos. }\end{array}$ \\
\hline comprometida & 2 & $\begin{array}{l}\text { La lengua se utiliza en algunos nuevos } \\
\text { ámbitos. }\end{array}$ \\
\hline mínima & 1 & $\begin{array}{l}\text { La lengua se utiliza sólo en unos pocos nuevos } \\
\text { ámbitos. }\end{array}$ \\
\hline inactiva & 0 & $\begin{array}{l}\text { La lengua no se utiliza en ningún nuevo } \\
\text { ámbito. }\end{array}$ \\
\hline
\end{tabular}

Fuente: UNESCO, 10.

El factor 6: Sobre la disponibilidad de materiales para el aprendizaje y la enseñanza de la lengua. Está en el nivel cero (ver cuadro 5).

Cuadro 5. Factor 6: Sobre la disponibilidad de materiales escritos

\begin{tabular}{|c|l|}
\hline Grado & \multicolumn{1}{|c|}{ Disponibilidad de materiales escritos } \\
\hline 5 & $\begin{array}{l}\text { Existen una ortografía establecida y una tradición de lectura y } \\
\text { escritura, con gramáticas, diccionarios, textos, literatura y medios de } \\
\text { comunicación diarios. La lengua escrita se utiliza en la administración } \\
\text { y en la educación. }\end{array}$ \\
\hline 4 & $\begin{array}{l}\text { Existen materiales escritos, y en la escuela los niños aprenden a } \\
\text { leer y escribir en la lengua. La lengua escrita no se utiliza en la } \\
\text { administración. }\end{array}$ \\
\hline 3 & $\begin{array}{l}\text { Existen materiales escritos y los niños pueden conocer la lengua escrita } \\
\text { en la escuela. No se promueve la alfabetización mediante medios } \\
\text { impresos. }\end{array}$ \\
\hline
\end{tabular}




\begin{tabular}{|c|l|}
\hline Grado & \multicolumn{1}{|c|}{ Disponibilidad de materiales escritos } \\
\hline 2 & $\begin{array}{l}\text { Existen materiales escritos, pero es posible que sólo sean útiles para } \\
\text { algunos miembros de la comunidad; para otros pueden tener un valor } \\
\text { simbólico. El aprendizaje de la lectura y la escritura en la lengua no } \\
\text { forma parte de los programas escolares. }\end{array}$ \\
\hline 1 & $\begin{array}{l}\text { La comunidad conoce una ortografía práctica y se escriben algunos } \\
\text { materiales. }\end{array}$ \\
\hline 0 & La comunidad no posee ninguna ortografía. \\
\hline
\end{tabular}

Fuente: UNESCO, 11.

En 2012 Quesada publicó su Gramática del buglere, estudio sintáctico, morfológico y fonético de la lengua (material no apto para la enseñanza directa de la lengua a niños). En 2016 se empezó con la producción de material escrito y didáctico para apoyar las clases que se empezaron a impartir el año anterior. El primer texto de una colección de tres, que presenta el primer nivel para el aprendizaje de la escritura y lectura en buglere, fue puesto a prueba por la maestra en 2018. A los niños y a la maestra se les dio un ejemplar en proceso de evaluación para obtener su retroalimentación en el uso diario; sin embargo, el uso de este material que se le dio la maestra en el proceso de evaluación no fue el óptimo debido a su falta de formación pedagógica. Los textos están actualmente en proceso de diseño y publicación, con el fin de que los niños dispongan de ellos en 2020, y en 2019 se impartirán talleres de formación pedagógica a la maestra con el fin de que pueda utilizar los libros con los niños de una mejor manera. Esto da cierta esperanza a la situación crítica del buglere, ya que de utilizarse los textos y correctamente, el buglere, con base en el factor de disponibilidad de materiales para la enseñanza y el aprendizaje, podría subir de un nivel dos al tercero.

El factor 7: Actitudes y políticas de los gobiernos y las instituciones hacia las lenguas, incluidos su rango oficial y su uso tiene una 
asimilación pasiva (cuadro 6). Bolaños ${ }^{19}$ describe algunas alternativas legislativas del gobierno de Costa Rica para el fortalecimiento y conservación de las lenguas indígenas del país. El Decreto Ejecutivo n. ${ }^{\circ} 18967$ establece que:

El Estado debe apoyar el rescate de las diferentes expresiones culturales, otorgando a los pueblos que conforman su nacionalidad, los recursos necesarios para el fomento, estudio y difusión de su cultura, incluyendo promoción y conservación de sus lenguas vernáculas ${ }^{20}$.

Se creó el Subsistema de Educación Indígena, en Ministerio de Educación Pública mediante el Decreto Ejecutivo n. ${ }^{\circ} 22072$ de 1993, cuyos objetivos son alfabetizar en leguas indígenas y promover la práctica de las mismas a través de estrategias para el rescate de las lenguas indígenas que se encuentren en proceso de muerte ${ }^{21}$. Más adelante, en la Resolución 34-97 de Consejo Superior de Educación, se instauran las asignaturas de lengua indígena y cultura indígena, con tres y dos lecciones semanales respectivamente. Se procura desarrollar habilidades de expresión oral y escrita en la lengua indígena, y promover el aprecio por la literatura oral indígena ${ }^{22}$. Pese a estas acciones altruistas, aún no se ven frutos para la revitalización de la lengua buglere.

El contar con una maestra de lengua, desde hace dos años, pero que no cuenta con formación pedagógica, agrava la situación y refleja que las intenciones gubernamentales no llegan a realizarse. La presencia del Ministerio de Educación Pública es real en todo el territorio nacional, como lo comenta Bolaños ${ }^{23}$ :

19 Isabel Cristina Bolaños Villalobos, «Gramática Pedagógica del Buglere: el primer paso para la revitalización de la lengua», UniverSOS. Revista de Lenguas Indígenas y Universos Culturales 14 (2017): 177-190 (184).

20 Carmen Rojas Chaves, «Revitalización lingüística de las lenguas indígenas de Costa Rica», Estudios de Lingüistica Chibcha 16, 9-17 (1997-1998): 9-17 (12).

21 Rojas Chaves, 12.

22 Bolaños, 184.

23 Bolaños, 185. 
El trabajo del Ministerio de Educación Pública ha llegado a los rincones más lejanos del país, incluyendo las comunidades en medio de la montaña donde viven los buglés. La falta [de infraestructura] no ha sido del MEP, sino de la misma carencia de valor e identidad propia de la población.

Ahora, la capacitación y compañía profesional se le brinda a la maestra de lengua. En 2018, Bolaños colaboró con la comisión de maestros de lenguas indígenas de la región en conjunto con la Asesora Nacional de Lenguas Indígenas del Ministerio de Educación Pública, que desarrollan los programas para la enseñanza y aprendizaje de la lengua guaymí. Su encargada indica que el diseño de los programas de enseñanza de lengua buglere no se pondrá en marcha antes de cuatro años. Este panorama revela que no existe una política explícita para las lenguas minoritarias; en el ámbito público prevalece la lengua dominante, lo que demuestra que dentro de este factor el rango oficial y el uso del buglere tienen una asimilación pasiva.

Cuadro 6. Factor 7: Sobre actitudes y políticas de los gobiernos e instituciones hacia la lengua

\begin{tabular}{|l|c|l|}
\hline Grado de apoyo & Grado & Actitudes oficiales hacia las lenguas \\
\hline apoyo igualitario & 5 & Todas las lenguas son protegidas. \\
\hline apoyo diferenciado & 4 & $\begin{array}{l}\text { Las lenguas minoritarias son protegidas } \\
\text { fundamentalmente como lenguas de ámbito } \\
\text { privado. El uso de la lengua es prestigioso. }\end{array}$ \\
\hline asimilación pasiva & 3 & $\begin{array}{l}\text { No existe una política explícita para las } \\
\text { lenguas minoritarias; en el ámbito público } \\
\text { prevalece la lengua dominante. }\end{array}$ \\
\hline asimilación activa & 2 & $\begin{array}{l}\text { El gobierno alienta la asimilación a la lengua } \\
\text { dominante. Las lenguas minoritarias no gozan } \\
\text { de protección. }\end{array}$ \\
\hline asimilación forzosa & 1 & $\begin{array}{l}\text { La lengua dominante es la única lengua } \\
\text { oficial, mientras que las lenguas no } \\
\text { dominantes no son reconocidas ni protegidas. }\end{array}$ \\
\hline prohibición & 0 & Las lenguas minoritarias están prohibidas. \\
\hline
\end{tabular}

Fuente: UNESCO, 13. 
El factor 9: Sobre la urgencia del trabajo de documentación: tipo y calidad de la documentación. Se considera que el buglere se encuentra entre las categorías pasable y fragmentaria (ver cuadro 7) ya que existe una gramática del buglere ${ }^{24} y$ se están diseñando los manuales para la enseñanza y aprendizaje del buglere para primero, segundo y tercer grados de escuela. Al carecer de medios de comunicación cotidianos en que se utilice la lengua, el alcance de estos materiales es mínimo. En la siguiente etapa del proyecto, se creará un repositorio de materiales lingüísticos anotados, tanto auténticos como didácticos, con el fin de compilar en forma centralizada, todos los estudios disponibles del buglere costarricense, así como los materiales didácticos producidos para fortalecer el proceso de revitalización que se está llevando a cabo.

Cuadro 7. Factor 9: Sobre la urgencia del trabajo de documentación

\begin{tabular}{|l|c|l|}
\hline $\begin{array}{c}\text { Naturaleza de la } \\
\text { documentación }\end{array}$ & Grado & \multicolumn{1}{|c|}{ Documentación de la lengua } \\
\hline excelente & 5 & $\begin{array}{l}\text { Existen gramáticas y diccionarios completos, } \\
\text { textos extensos y un flujo constante de materiales } \\
\text { lingüísticos. Hay abundantes registros anotados de } \\
\text { audio y vídeo de alta calidad. }\end{array}$ \\
\hline buena & 4 & $\begin{array}{l}\text { Existen una buena gramática y cierto número } \\
\text { de gramáticas aceptables, diccionarios, textos, } \\
\text { literatura y medios de comunicación cotidianos; } \\
\text { hay suficientes registros anotados de audio y vídeo } \\
\text { de alta calidad. }\end{array}$ \\
\hline pasable & 3 & $\begin{array}{l}\text { Puede haber una gramática aceptable o un número } \\
\text { suficiente de gramáticas, diccionarios y textos, } \\
\text { pero no medios de comunicación cotidianos; } \\
\text { pueden existir registros de audio y vídeo de } \\
\text { calidad variable o diverso grado de anotación. }\end{array}$ \\
\hline
\end{tabular}

24 Quesada (2012). 


\begin{tabular}{|l|c|l|}
\hline $\begin{array}{c}\text { Naturaleza de la } \\
\text { documentación }\end{array}$ & Grado & \multicolumn{1}{|c|}{ Documentación de la lengua } \\
\hline fragmentaria & 2 & $\begin{array}{l}\text { Hay algunos esbozos de gramática, listas de } \\
\text { palabras y textos de utilidad para una investigación } \\
\text { lingüística limitada, pero sin suficiente cobertura. } \\
\text { Pueden existir registros de audio y vídeo de } \\
\text { calidad variable, con o sin anotación. }\end{array}$ \\
\hline insuficiente & 1 & $\begin{array}{l}\text { Existen sólo unos pocos esbozos de gramática, } \\
\text { breves listas de palabras y textos fragmentarios. } \\
\text { No hay registros de audio y vídeo, o los que hay } \\
\text { son de calidad inutilizable o carecen totalmente de } \\
\text { anotación. }\end{array}$ \\
\hline indocumentada & 0 & No existe ningún material. \\
\hline
\end{tabular}

Fuente: UNESCO, 17.

El factor 8: Actitudes de los miembros de la comunidad hacia su propia lengua. En la población buglé de San Vito de Coto Brus son muy pocos los miembros que demuestran interés por preservar su lengua. La población bugle muestra una baja autoestima lingüística. La mayoría es indiferente o inconsciente del proceso de extinción que atraviesa el buglere. Desde el dominio cultural y social que el guaymí ejerce, los buglés no encuentran ningún beneficio al hablar la lengua; no es esencial para sobrevivir. Por tanto, no lo consideran necesario o importante. En suma, la actitud de los hablantes del buglere está en grado dos (ver cuadro 8): o sea que «algunos miembros apoyan el mantenimiento de la lengua; otros son indiferentes o pueden incluso apoyar su pérdida» ${ }^{25}$.

25 Aunado a esto, los niños no tienen clara su propia situación; dicen «yo soy buglé; hablo buglere», pero cuando se les pide que hablen, lo hacen en guaymí. Los niños corrigen el material lingüístico que se les presenta; incluso la maestra corrige palabras sustituyéndolas por sus versiones guaymíes. El lenguaje de la maestra incluye guaymismos. En una observación de clase, la maestra al frente en la pizarra se dirigió a las observadoras, diciendo: «¿Verdad que ustedes hablan en murire?». (murire: buglere en guaymí). O sea, la maestra se refiere a su propia lengua con el nombre de esta en otro idioma. 
Cuadro 8. Factor 8: Sobre las actitudes de los miembros de la comunidad hacia su propia lengua

\begin{tabular}{|c|l|}
\hline Grado & Actitudes de los miembros de la comunidad hacia su lengua \\
\hline 5 & $\begin{array}{l}\text { Todos los miembros conceden valor a su lengua y desean que se } \\
\text { promueva. }\end{array}$ \\
\hline 4 & La mayoria de los miembros apoyan el mantenimiento de la lengua. \\
\hline 3 & $\begin{array}{l}\text { Muchos miembros apoyan el mantenimiento de la lengua; otros son } \\
\text { indiferentes o pueden incluso apoyar su pérdida. }\end{array}$ \\
\hline 2 & $\begin{array}{l}\text { Algunos miembros apoyan el mantenimiento de la lengua; otros son } \\
\text { indiferentes o pueden incluso apoyar su pérdida. }\end{array}$ \\
\hline 1 & $\begin{array}{l}\text { Sólo unos pocos miembros apoyan el mantenimiento de la lengua; } \\
\text { otros son indiferentes o pueden incluso apoyar su pérdida. }\end{array}$ \\
\hline 0 & $\begin{array}{l}\text { A nadie le preocupa que se pierda la lengua; todos prefieren emplear } \\
\text { una lengua dominante. }\end{array}$ \\
\hline
\end{tabular}

Fuente: UNESCO, 13

\section{7: El buglere: lengua indiferente}

En 2009, Quesada sostenía que el buglere es una lengua en serio peligro de extinción, o en un estado intermedio entre declinación y obsolescencia según la tipología de Bauman ${ }^{26}$. Si se extrapola esa tipología a los factores de la UNESCO para evaluar la vitalidad de una lengua, partiendo de las observaciones desarrolladas en los últimos dos años mediante el trabajo continuo realizado con la población buglere de San Vito de Coto Brus, el buglere ha descendido un nivel y ha llegado al estado de indiferencia, revelando su continuo estado de degradación. Se destaca el aspecto actitudinal de los hablantes bugle en Costa Rica. La descripción de la población buglere de Bolaños ejemplifica características de la población que llevan a su categorización en el estado «indiferente» ${ }^{27}$.

La lengua buglere no se utiliza sino en forma ocasional. La mayoría de las familias son interculturales (los guaymíes y los buglés

26 Bauman, 16.

27 Bolaños, 179. 
se han mezclado); el bilingüismo unidireccional hace que los niños de esas familias se consideren guaymíes y utilicen esa lengua como materna. En las entrevistas con los niños se puede notar que la mayoría convive aún en ambientes íntimos donde oyen algo de buglere en su vida cotidiana, por lo que han desarrollado cierta capacidad receptiva de la lengua, pero la demanda social y cultural de producirlo es casi nula. Esta generación no emplea la lengua como herramienta de comunicación en el ámbito fuera de su hogar; su uso se ha trasladado a pocas funciones de comunicación, o sea la lengua ya no es una herramienta de producción sino de recepción - escasa - de información.

Lo más perjudicial es la «vergüenza lingüística» que caracteriza los hablantes indiferentes. En el caso del buglere, se ha notado esta actitud incluso en la maestra de la lengua. En varias oportunidades no se ha detectado un interés más allá del económico al enseñar la lengua buglere. Además, los pobladores bugles carecen de iniciativa para preservar su lengua. El informante principal de proyecto es el único interesado en la revitalización lingüística, pero se percibe cierto aislamiento de la organización social y cultural de la población. En resumen, en tan sólo un poco más de una década se ha visto la degradación del estado de la lengua buglere, con lo cual el proceso de declive se encuentra próximo a su compleción.

\section{Conclusiones}

a. Así como existen lenguas cuyo proceso de declive se da en espacios prolongados de tiempo, otras, como en el caso del buglere, dejan de existir en cuestión de una década.

b. Bauman ${ }^{28}$ considera que disminuir el ritmo, detener o revertir el proceso de extinción de una lengua son posibles siempre y cuando la comunidad hablante lo desee, el estado de la lengua

28 Bauman, 11. 
y las razones de su declive lo permitan y que se cuente con fondos destinados a tal tarea. Hoy en día los requisitos siguen siendo los mismos y con base en lo expuesto se seguirá trabajando en el Proyecto Gramática Pedagógica del Buglere, para utilizar los escasos recursos disponibles a sabiendas que no bastan para revertir el proceso de declive ya muy avanzado.

c. Se ha concluido que revitalizar en la clase no será la respuesta al problema, por lo que una opción más efectiva para detener el proceso sería una estrategia de inmersión lingüística conocida como «Casa Cuna», mediante la que se crea un ambiente donde los niños sientan la necesidad de utilizar la lengua para comunicarse y sobrevivir. Este proceso se desarrolla con niñeras cuidadoras que utilicen el buglere como lengua primaria, y donde se acuda a la lengua para jugar, aprender y crecer. El aprendizaje en un ambiente totalmente natural es la única posibilidad de acción disponible. 
